\title{
PRAÇAS DE VITÓRIA
}

\author{
VITÓRIA'S OPEN SPACES
}

\section{BOTECHIA, Flávia Ribeiro}

Arquiteta (UFES, 1998), mestre em arquitetura e urbanismo (UFMG,2001). Professora do curso de Arquitetura e Urbanismo do Centro de Educação UNIVIX - Vitória (ES). Arquiteta do Departamento de Projetos Urbanísticos - Prefeitura Municipal de Vitória (ES). E-mail: fbotechia@bol.com.br

\section{JORGE, Liziane de Oliveira}

Arquiteta (UFES, 1999), mestre em arquitetura e urbanismo (UFMG,2004). Professora do curso de Arquitetura e Urbanismo das Faculdades Integradas Nacional - FINAC - Vitória (ES). Arquiteta do Departamento de Projetos Urbanísticos - Prefeitura Municipal de Vitória (ES). E-mail: lizianejorge@terra.com.br

Equipe: Engenheira Clívia Leite Mendonça, arquitetos Msc. Anna Claudia Dias Peyneau, arquitetos Flávia Pulcheri Ribeiro, Fabrício Sanz Encarnaçāo, Natielly Dório, Larissa Goya Billotta, Bruno Borges, Sabrina Bassani de Oliveira (estagiários de arquitetura).

\section{RESUMO}

O objetivo deste trabalho foi cadastrar os espaços livres de uso público existentes na cidade de Vitória, com intuito de qualificar a prática projetual das áreas públicas e favorecer o conhecimento das áreas urbanas. Na atual nomenclatura adotada pelo município, são igualmente classificadas como praças áreas destinadas ao lazer da população quanto uma rotatória, resultante de intervenção viária. Este fato constitui-se também uma problemática de pesquisa, redefinindo estratégias de classificação e registro de áreas públicas. Nas diversas administrações municipais, a cidade de Vitória recebeu projetos de requalificação e intervenção nos espaços livres de uso público chegando atualmente a um momento que requer, e permite, a caracterização desta produção urbanística.

\section{Palavras-chave: Urbanismo, georeferenciamento, planejamento urbano.}

\begin{abstract}
The objective of this work was to register in cadastre existing the spaces of public use in the city of Vitória, with intention to characterize the practical projetual of the public areas and to favor the knowledge of the urban areas. In the current nomenclature adopted for the city, equally squares are classified as areas destined to the leisure of the green areas and gardens along roads. This fact also consists problematic of research, redefining strategies of classification and register of public areas. In the diverse municipal administrations, the city of Vitória received projects from requalification and urban intervention in the spaces of public use arriving currently at a moment that it requires, and allows, the characterization of this local urban production.
\end{abstract}

Key words: Urbanism, public areas, urban planning.

Categorizada como um dos elementos morfológicos do espaço urbano, a praça é o local do encontro e do lazer nas cidades. Nas diferentes épocas históricas as praças foram palco dos diferentes hábitos da sociedade, sofreram mudanças em sua estrutura projetual, linhas estruturais, passando sempre por intervenções que refletiram diferentes cidades, hábitos, culturas. E assim criaram paisagens e ambiências urbanas.

Ao longo de séculos, a "praça brasileira", adquiriu novos programas, usos, padrões funcionais e formais, referências estéticas. Vitória, capital do estado do Espírito Santo, assim como as demais cidades brasileiras, passou por um processo de transformação de seu espaço urbano, que vai desde o largo em frente a lgrejas e para troca de mercadorias, no período colonial, até a praça contemporânea, com seus diversos apelos projetuais. 
Nas diversas administrações municipais, a cidade de Vitória recebeu projetos de embelezamento e intervenção nos espaços livres de uso público chegando atualmente a um momento que requer, e permite, a caracterização desta produção urbanística.

\section{Justificativa}

No caso brasileiro, praças podem ser definidas por "[...] espaços livres públicos destinados ao lazer e ao convívio da população, acessíveis aos cidadãos e livres de veículos" (MACEDO; ROBBA, 2003, p. 17). Tendo, o espaço urbano, recebido intervenções através do trabalho humano, as praças revelam intenções, desejos e diretrizes que criam a história da cidade. Considerando o momento presente, no processo de planejamento e desenvolvimento das cidades e de novas praças e/ou áreas de lazer, os projetos existentes, seus elementos e programa projetual, público freqüentador, estado de conservação, além de sua inserção na malha urbana.

Na atual nomenclatura adotada pelo município (não diferentemente de outras cidades brasileiras), são igualmente classificadas como praça, por exemplo, tanto a "Praça dos Namorados" (um grande empreendimento de alcance metropolitano situado na administração regional 5 - Praia do Canto), quanto uma rotatória, resultante de intervenção viária. Este fato constitui-se também uma problemática de pesquisa, redefinindo estratégias de classificação e registro de áreas públicas.

Associada à complexidade das definições, a inexistência de uma fonte de consulta que pudesse reunir os dados referentes às praças da cidade de Vitória foi o propulsor para o desenvolvimento do trabalho.

Conhecer a cidade é fundamental para nela intervir com critérios renovados, na tentativa de adquirir subsídios técnicos para futuras tomadas de decisão de planejamento e projetos. $\mathrm{Na}$ atual estrutura da Prefeitura Municipal de Vitória, administram, projetam e mantém as praças, as Secretarias de Desenvolvimento da Cidade, Meio Ambiente e sete administrações regionais (Figura 1), divididas em vários bairros.

\section{Objetivos}

O objetivo geral deste trabalho foi definido por cadastrar os "espaços livres públicos destinados ao lazer e ao convívio da população"l existentes na cidade de Vitória, com intuito de qualificar a prática projetual das áreas públicas.

É possível também definir como objetivo específico, categorizar os espaços públicos existentes segundo os critérios de uso e acessibilidade. Como finalidade, por parte do poder público, está a circulação de informações para o público geral da produção dos espaços públicos na cidade, em uma rede verde, além do necessário conhecimento do espaço para o planejamento urbano, de forma técnica. Para o público, ficaria muito perceptível o objetivo quando da publicação de material através da criação de folders e informações na internet.

As metas colocadas ao desenvolvimento do projeto foram:

- Cadastrar todos os espaços públicos existentes na cidade de Vitória até março 2005;

- Cadastrar os espaços públicos existentes na cidade de Vitória definindo tipologia urbanística, chegando ao conceito, áreas verdes, configuração e elementos complementares até março 2005;

\section{Metodologia}

Para embasar teoricamente a realização e fundamentação deste projeto foram utilizadas metodologias aplicáveis à observação e registro de espaços públicos. 


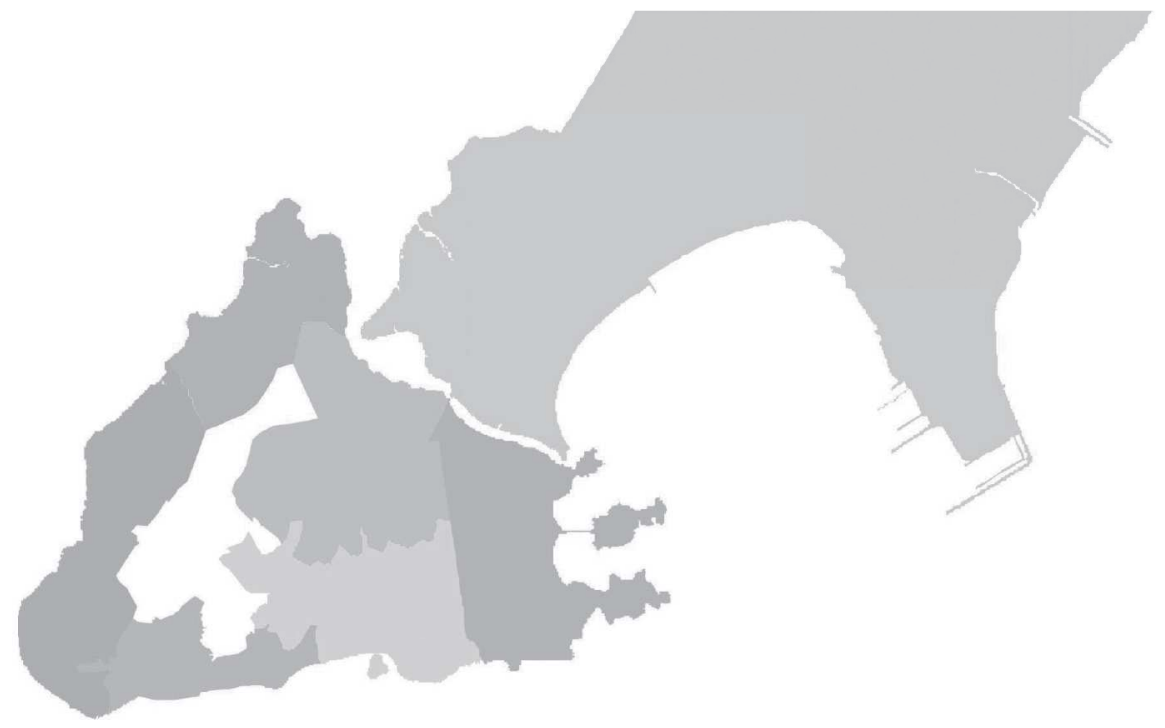

Figura 7: Mapa da cidade de Vitória (ES) com subdivisão de administrações regionais Fonte: PMV, 2005

Conceitos e exemplos de praças, recortes históricos e espaciais, foram estudados recorrendo, principalmente, às informações disponibilizadas pelo Projeto "Quapá", desenvolvido pelos Professores Silvio Soares Macedo e Fábio Robba (Universidade de São Paulo, 1994-2001), e equipe. Esta literatura traça um registro do Quadro do Paisagismo no Brasil (1999), apresentando metodologia de cadastro e categorização de praças brasileiras, séculos XIX e XX.

Nesta linha teórica, recorreu-se a definição de "praça" uma vez que foi identificado no planejamento um equívoco quanto ao registro de áreas públicas criadas. Foram criadas ao longo de anos, pequenas praças, parques, jardins, canteiros centrais e rotatórias (criadas em função de projetos viários) sob a mesma definição de praça, o que pode criar, por sua vez, indicadores urbanos equivocados.

Além do registro da nomenclatura, há a possibilidade de pesquisa da produção urbanística local, classificação de estilos e formas, materiais mais ou menos adequados ao projeto urbanístico segundo padrões locais. Abre-se perspectiva para uma análise pós-ocupação como desdobramento desta pesquisa inicial.

Outro desdobramento seria a análises espacial e tipológica, contemplando no contexto da malha urbana os deslocamentos, centralidade, mobilidade e análise da tipologia de espaços urbanos como descreve:

"Do primitivo rossio junto à Igreja no início da ocupação do território no século XVI [...], à praça cívica comemorativa da consolidação da República da década de 20, as praças da cidade sofreram inúmeras modificações geométricas e estéticas, sem, no entanto, impedir que se identifiquem seus tipos [...]." (RODRIGUES, 2005, p. 74)

Os softwares utilizados foram os disponíveis nas versões da Prefeitura de Vitória.

Para atingir os objetivos propostos adotou-se etapas para desenvolvimento deste projeto "Praças de Vitória", assim podendo ser preliminarmente descritas:

1. Levantamento de áreas públicas existentes no município de Vitória - nos limites das administrações regionais, através de entrevistas a técnicos, visitas a campo, coleta geral de informações;

2. Levantamento dos layers de ARCVIEW SIG 3.2 existentes no âmbito da administração municipal que tivessem correspondência ao tema em questão: "praças" da SEMMAM - Secretaria de Meio Ambiente (por ponto), "usos do solo" da SEDEC2, "limites de bairro" da SEDEC, "vias pavimentadas e não pavimentadas", "limites de regionais"; 
3. Rebatimento entre dados dos layers;

4. Questionamentos e investigação sobre o por quê de determinadas informações dos layers não terem correspondência/ rebatimento entre si;

5. Consulta a decretos e leis municipais sobre a criação de praças;

6. Definição de um conceito, fundamentado em urbanismo, sobre o que é uma praça;

7. Criação do projeto PRAÇAS com layers base desenvolvidos pela SEDEC;

8. Alimentação do projeto com criação de layer praças, com polígonos, usando a base dos lotes;

9. Classificação das áreas públicas existentes no município de Vitória em praça, praça passagem, praça não urbanizada, rua jardim, jardim urbano, parque natural municipal, parque urbano municipal;

10. Alimentação do layer praças, com criação de tabela e inserção de dados: nome, código, decreto/lei, bairro, localização/ endereço, regional, área, classificação;

11. Criação de código por praça: [número da regional] + [inicial do primeiro nome] + [inicial do segundo nome];

12. Ida a campo a fim de verificar o local com base no novo conceito urbano adotado de "Praça", registro fotográfico, croqui de observação (em planta) e preenchimento de tabela com configurações urbanas, materiais empregados, equipamentos existentes;

13. Criação de banco de dados complementar no MICROSOFT ACCESS, para registro das informações sobre as configurações urbanas, contemplando: foto, regional, área estimada, elementos de composição, caracterização do entorno, edificações existentes, manutenção, atividades. Foi utilizado o mesmo código do ARCVIEW SIG;

14. Registro dos croquis, por regional, em banco de dados do CORELDRAW v.11 a partir de base digital da cidade de Vitória em AUTOCAD;

15. Impressão do material produzido para elaboração de relatório interno;

16. Encaminhamento do projeto "Praças" em ARCVIEW SIG e banco de dados no MICROSOFT ACCESS para o SUBTI (Gestão de Tecnologia da Informação) da SEMFA ${ }^{3}$ para análise e possível incorporação ao banco de dados da Prefeitura;

17. Encaminhamento do projeto "Praças" em ARCVIEW SIG e banco de dados no MICROSOFT ACCESS para o SUBTI (Gestão de Tecnologia da Informação) da SEMFA para análise e possível incorporação ao GEOWEB ${ }^{4}$ da Prefeitura;

O produto que se apresenta é o início de um processo que pretende conhecer e registrar a produção do espaço público no município de Vitória. Deverá assim ser constantemente alimentado e tornar-se base única da Prefeitura de Vitória chegando assim à proposta do planejamento urbano integrado.

\section{Resultados}

A partir dos levantamentos em campo e nos escritórios das regionais, os espaços públicos foram classificados em diferentes conceitos segundo a morfologia urbana e a configuração da urbanização existente (Tabela 1).

Das iniciais duzentas e quarenta e três áreas públicas pesquisadas, foi possível obter a seguinte classificação por nomenclatura: 


\begin{tabular}{|l|c|}
\hline PRAÇAS POR CONCEITO & QUANTIDADE \\
\hline CLASSIFICAÇÃO & 20 \\
\hline Jardim urbano & 5 \\
\hline Parque Natural Municipal & 8 \\
\hline Parque Urbano Municipal & 165 \\
\hline Praça & 9 \\
\hline Praça não urbanizada & 3 \\
\hline Praça de passagem & 33 \\
\hline Rua jardim & 243 \\
\hline TOTAL & \\
\hline
\end{tabular}

Tabela 1: Conceitos utilizados na classificação e cadastro de praças no município de Vitória (ES) Fonte: Pesquisa de campo, 2004

Entende-se por jardim urbano, áreas ajardinadas da cidade sem mobiliário urbano e indicação de área de permanência. Entende-se por praça de passagem, áreas urbanizadas sem locação de mobiliário, localizadas em áreas de grande fluxo de veículos, com estacionamento (Figuras 2 e 3). Por sua vez, ruas-jardim são ruas sem saída com pequenos canteiros ou jardineiras ao final delas, impedindo a passagem de veículos e promovendo a urbanização das mesmas. Este último exemplo pode ser encontrado no bairro Mata da Praia, enquanto as praças de passagem são mais freqüentes na área central.

Em números absolutos, ou seja, sem fazer relação com a área das administrações regionais $\left(\mathrm{m}^{2}\right)$, pode-se considerar o seguinte número de praças por regional (Tabela 2):

\begin{tabular}{|l|c|c|}
\hline \multicolumn{2}{|l|}{ PRAÇAS POR REGIONAL (em números absolutos) } & $\%$ \\
\hline REGIONAL & QUANTIDADE & 16,05 \\
\hline 1 - Centro & 27 & 16,05 \\
\hline 2 - Santo Antônio & 27 & 11,3 \\
\hline 3 - Bento Ferreira & 19 & 13,1 \\
\hline 4 - Maruípe & 22 & 10,1 \\
\hline 5 - Praia do Canto & 17 & 28,6 \\
\hline 6 - Continental & 48 & 4,8 \\
\hline 7 - São Pedro & 8 & 100 \\
\hline TOTAL & 168 & \\
\hline
\end{tabular}

Tabela 2: Número absoluto de praças por administração regional do município de Vitória (ES)

Fonte: Pesquisa de campo, 2004

Para efeito de cadastro, utilizou-se como suporte programas de computador como ARCVIEW SIG, MICROSOFT ACCESS, CORELDRAW e AUTOCAD.

Nos levantamentos de campo foi preenchida uma tabela com caracterização da estrutura e equipamentos das praças, além de croquis de observação (desenhos sem escala) da configuração do desenho urbano. Estas informações foram transpostas, respectivamente, em MICROSOFT ACCESS e CORELDRAW.

No processo de investigação do elemento urbano foi observado que algumas praças foram criadas pelo poder público municipal através de decretos, porém outros não, podendo ter sido 


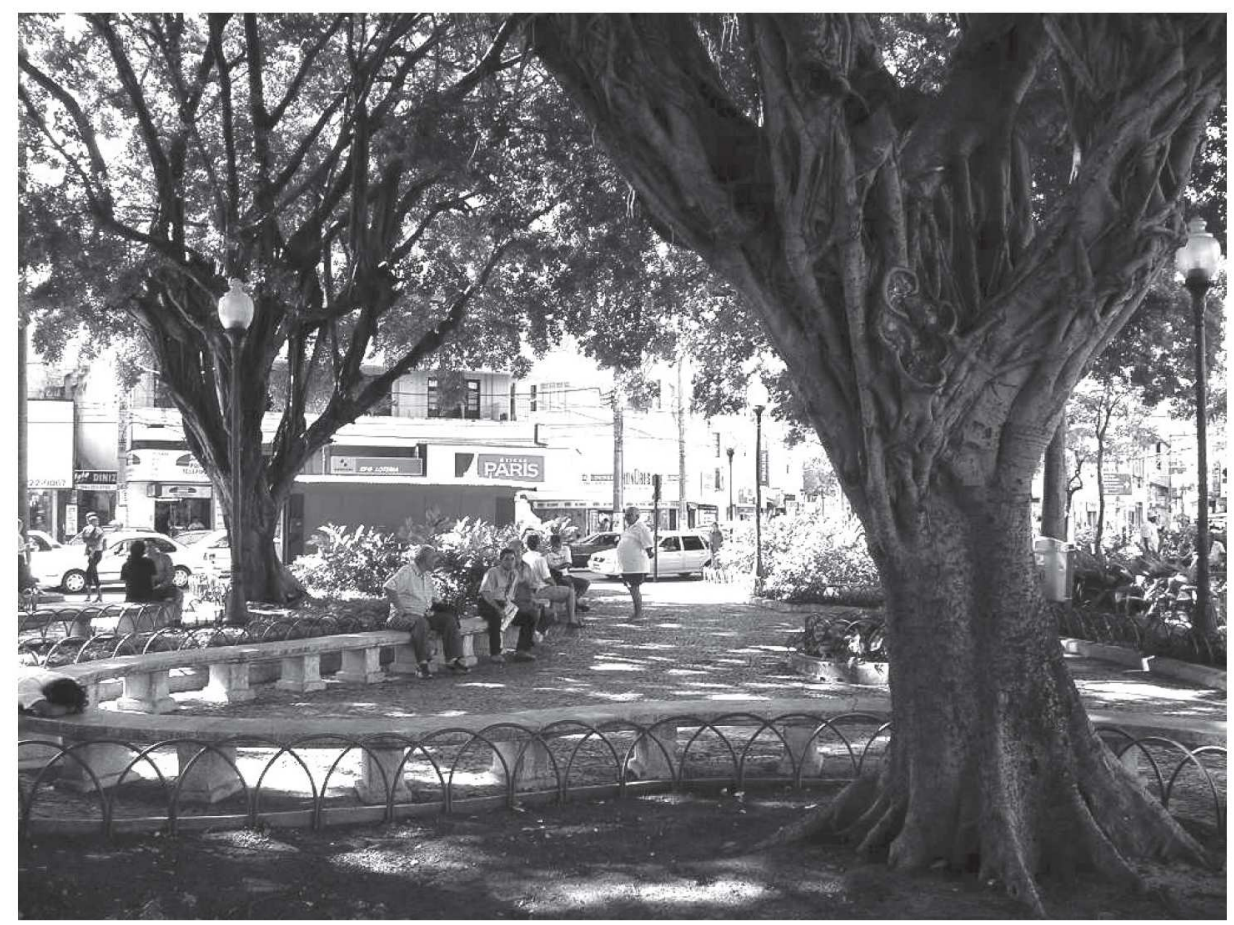

Figura 2: Praça Costa

Pereira - centro de

Vitória

Fonte: PMV, 2004

fruto de outras maneiras de intervenção. Não foi identificado um decreto para cada praça, instituindo um nome oficial, quando isto ocorre o nome popular, ou o nome da Rua onde esta está localizada, foi preservado no registro.

Foi elaborado um relatório parcial do trabalho, por regional, cada praça com, pelo menos, uma ficha ou um croqui, observando o que foi dito anteriormente: quando da não existência do nome oficial da área instituído por legislação, foi preservado o nome popular, entre parênteses, e o nome da Rua, entre aspas.

Os registros deverão ser sempre atualizados quando de reforma das praças existentes ou criação de novas áreas, configurando desta forma um efetivo banco de dados, objetivo principal deste trabalho. Pretende-se que outras informações, principalmente as referentes ao meio ambiente, posam em breve compor este catálogo.

Para efeitos de registro das informações coletadas em campo, foi desenvolvido no programa Microsoft Access, um banco de dados identificando características mais específicas das praças:

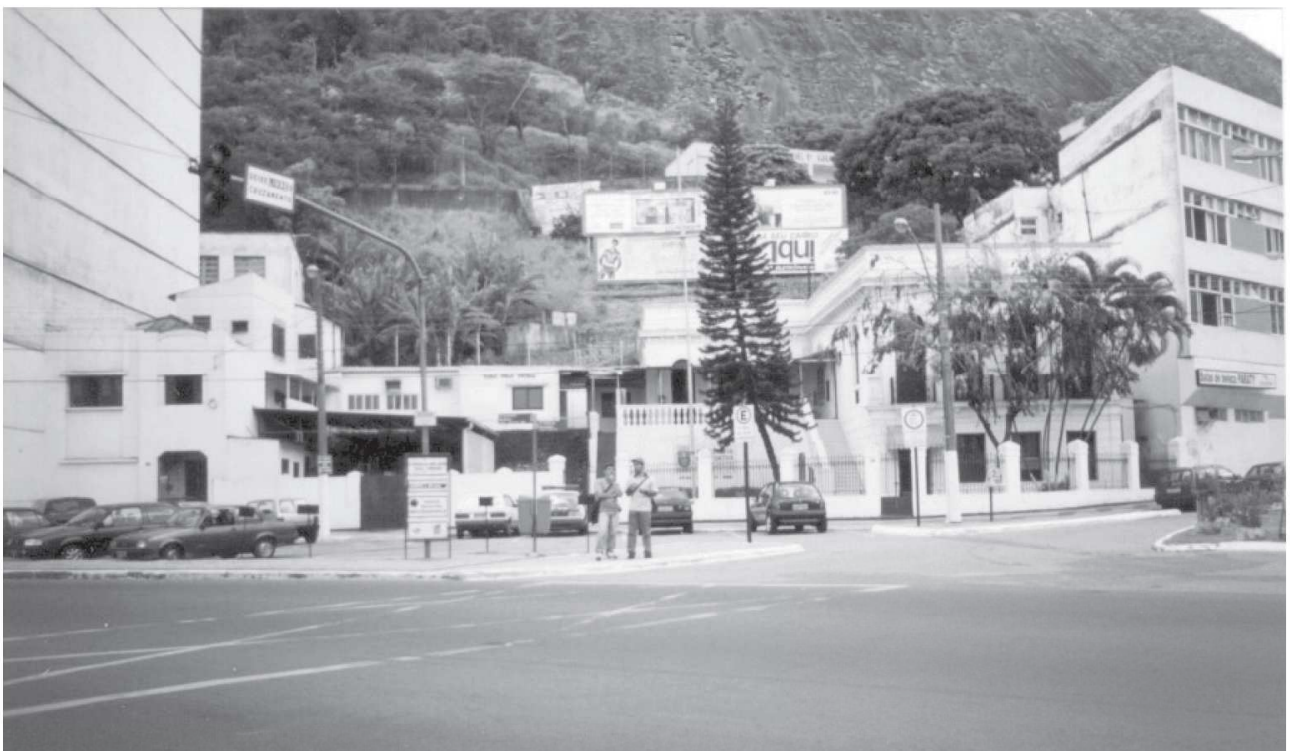

Figura 3: Praça Manoel Silvino Monjardim, criada pelo Decreto $5.383 / 73$, localizada no centro da cidade e classificada como "praça-passagem" por se constituir em área destinada a estacionamento da "Casa Porto de Artes Plásticas"

Fonte: PMV, 2004 
foto, administração regional, área estimada, elementos de composição, caracterização do entorno, edificações existentes, manutenção, atividades contemplativa ou recreativa. A Figura 4 representa um espelho deste cadastro:

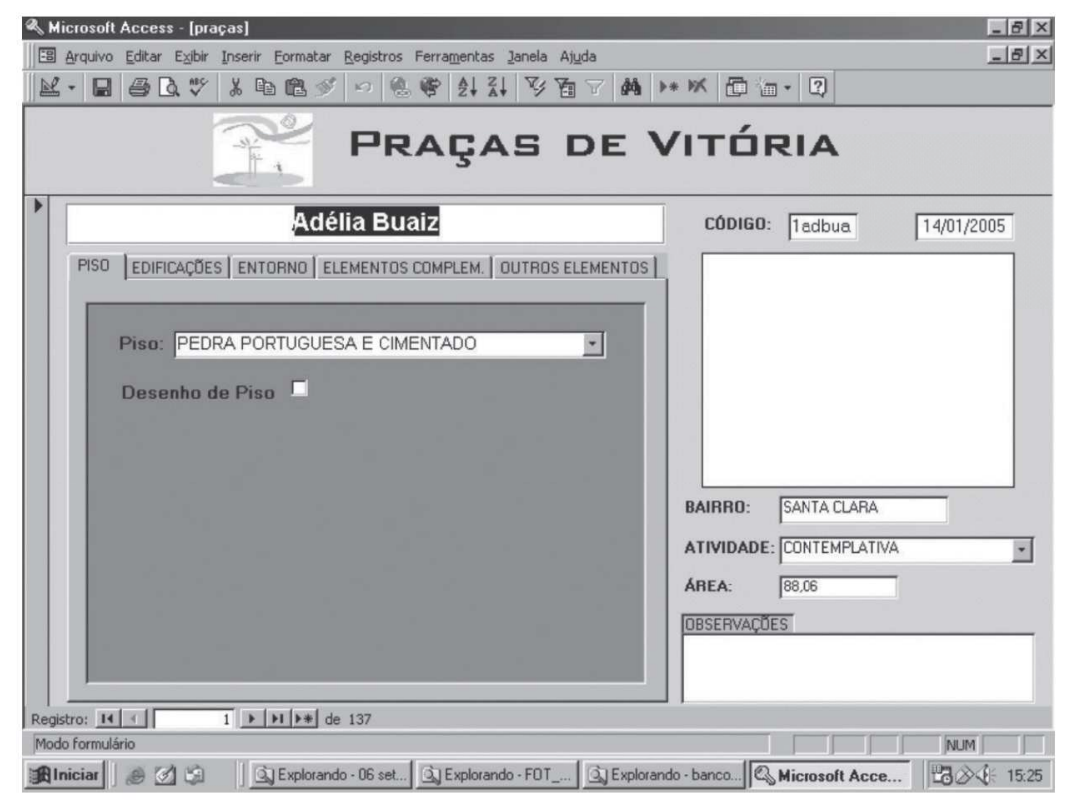

Figura 4: Ficha cadastral de praças por administração regional do município de Vitória (ES) - modelo do access Fonte: PMV, 2005

No registro das informações em ARCVIEW GIS 3.2, foram criados layers e utilizados layers criados na revisão do Plano Diretor Urbano da cidade de Vitória (2003-2005). O mapeamento seguiu um modelo representado pela Figura 5.

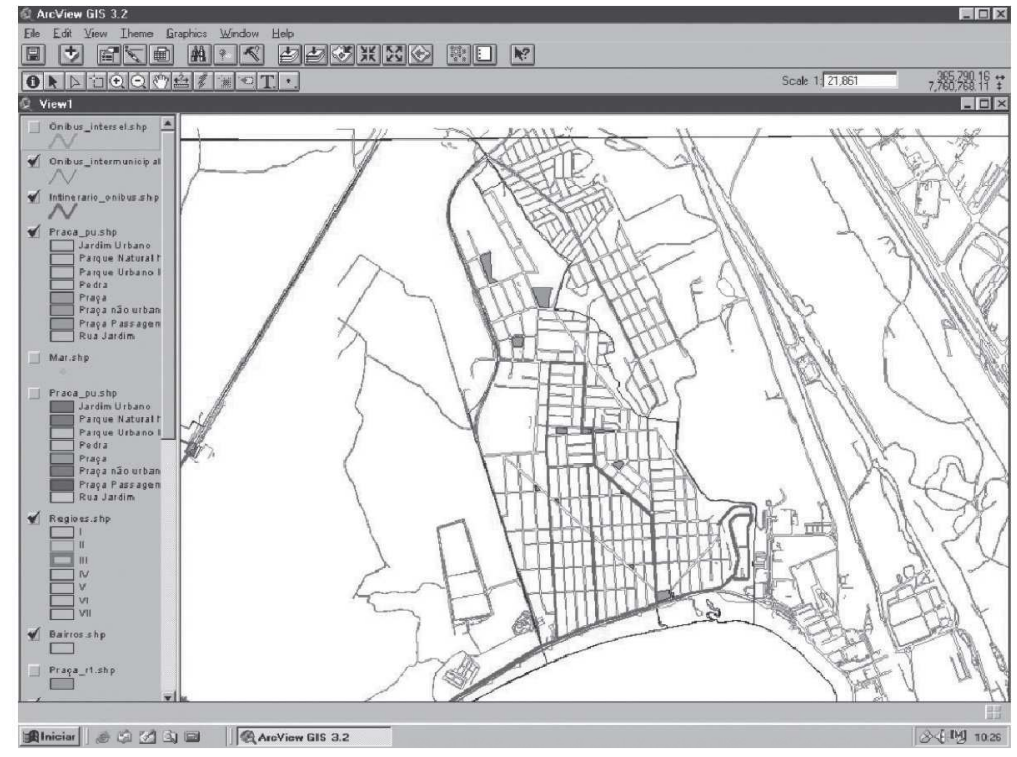

Figura 5: Projeto "Praças" do município de Vitória (ES) - modelo destacando o bairro Jardim Camburi no arcview Fonte: PMV, 2005

No ano de 2003, foram feitas entrevistas com técnicos das administrações regionais para mapeamento das áreas de lazer existentes, o que resultou em um mapa chave com as primeiras anotaçōes sobre as áreas públicas. Neste mesmo momento foram elaboradas tabelas para futura pesquisa de campo e tabulação de dados.

Em 2004, a metodologia para pesquisa de campo foi definida e o processo de visita às áreas previamente marcadas foi feito de acordo com a divisão administrativa do município, ou seja, por regionais. Após o registro inicial, os dados obtidos foram georeferenciados em ARCVIEW GIS 3.2 e os croquis de observação elaborados foram transpostos em base do CORELDRAW (Figuras 6 e 7). Às informações do ARCVIEW foram vinculadas informações do banco de dados criado em MICROSOFT ACCESS para registro mais detalhado de informações obtidas em campo. 

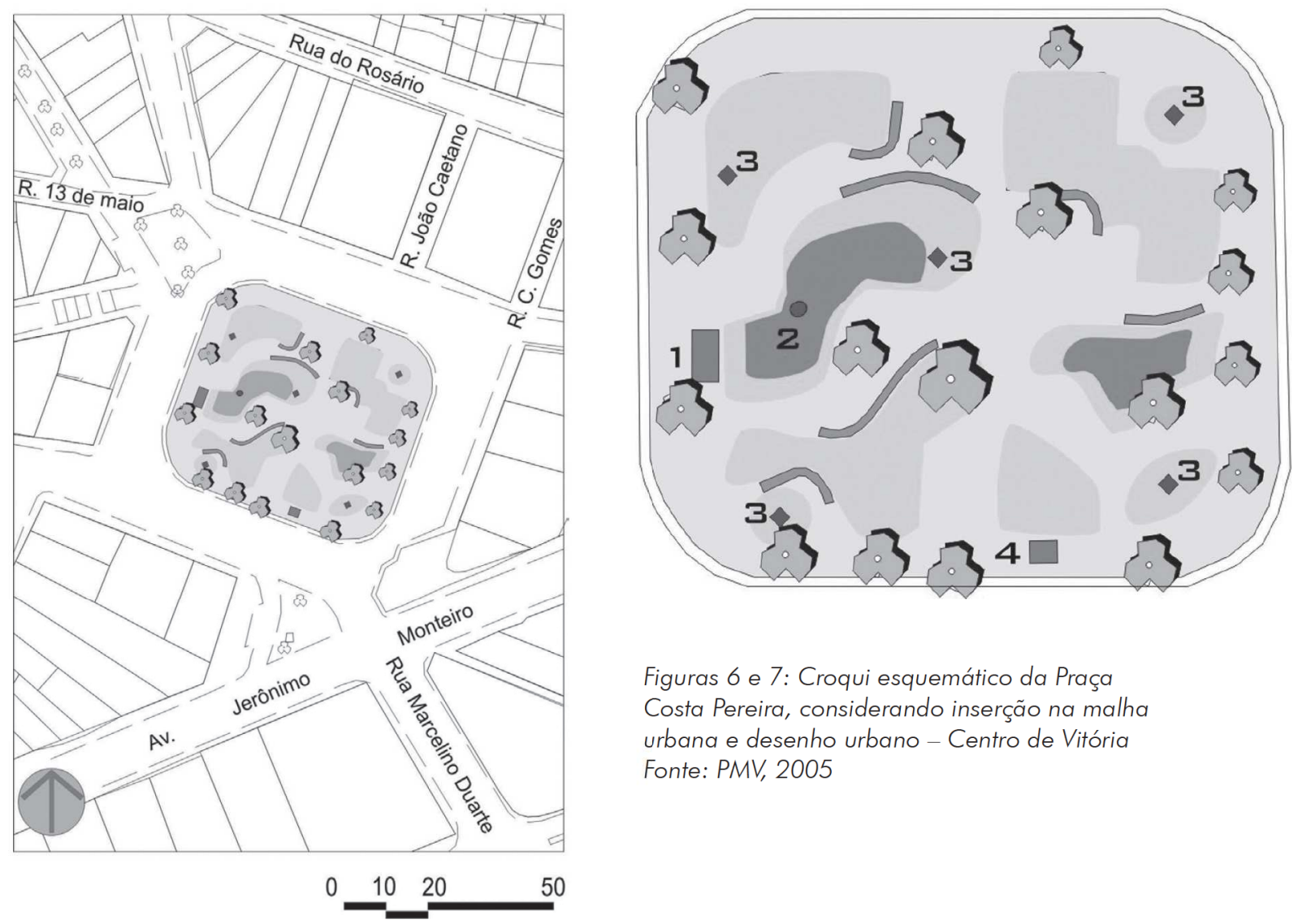

Figuras 6 e 7: Croqui esquemático da Praça Costa Pereira, considerando inserção na malha urbana e desenho urbano - Centro de Vitória Fonte: PMV, 2005

O banco de dados criado traduz completamente as informações obtidas em campo tais como configuração espacial, projeto urbano, entorno imediato, localização. Os dados do ARCVIEW aparecem de forma compacta e vinculados aos propósitos do programa e do planejamento urbano.

Junto a esse trabalho foram desenvolvidas análises das praças no contexto de bairros e da malha urbana, tendo como ensaio o bairro Jardim Camburi localizado, à época, na regional administrativa seis. $O$ estudo urbanístico para este bairro gerou diagramas analíticos, textos descritivos e uma "folheteria" específica sobre as praças existentes na área, criando uma rede verde perceptível ao morador ou usuário.

A criação de logomarca do projeto deu corpo e identidade ao trabalho desenvolvido, permitindo inclusive os referidos ensaios no contexto do "Praças de Vitória".

Em 2005 foram finalizados o trabalho de campo e o registro fotográfico, grosso modo. Ainda é preciso rever questões de fotografias e voltar à algumas áreas fazendo o refino necessário e desejável. Foram igualmente finalizadas a primeira etapa de alimentação de dados em ARCVIEW GIS 3.2, MICROSOFT ACCESS E CORELDRAW e elaborado modelo de informações sobre as praças com vistas a uma publicação sobre as "Praças de Vitória".

Atualmente o banco de dados, desenvolvido na Secretaria de Desenvolvimento da Cidade, foi incorporado ao banco de dados da Prefeitura Municipal o que resultou em ajustes (concluídos e a iniciar) fato que permitiu o alcance do objetivo da disponibilização de informações de forma ampliada.

194 Vale ressaltar que a Secretaria Municipal de Meio Ambiente encontra-se no caminho de compartilhar as informações sobre as áreas públicas municipais alimentando este mesmo banco de dados com as características de áreas verdes, cobertura vegetal e manutenção, serviço por eles realizado periodicamente. 


\section{Considerações finais}

"Projeto Praças de Vitória" apresenta um salto no que diz respeito à compatibilização da informação real, física e da digitalização da mesma. Como uma das premissas do mundo contemporâneo, o computador atua como mediador da informação e permite agilidade no processo de divulgação da informação. A interface entre o "lócus" geo-referenciado de cada praça e seus componentes em escala "micro" são inseridos no software ARCVIEW GIS, que permite a atualização constante da informação - compatível com o acelerado processo de transformação que o espaço urbano sofre na contemporaneidade.

O caráter pedagógico do projeto conta com a possibilidade da divulgação através do site da Prefeitura Municipal de Vitória do design de cada praça, com plantas ilustrativas enriquecidas com simbologias referentes aos equipamentos e estrutura correspondente, fotos, assim como o acesso ao banco de dados que caracteriza detalhadamente cada espaço público classificado.

Todos saem favorecidos, os cidadãos, que poderão desvendar os meandros do espaço público da cidade e a municipalidade, que através do mapeamento detalhado de cada praça, pode definir estratégias, planos e ações relacionadas ao espaço urbano circundante.

\section{Notas}

(1) A definição urbanística adotada de "praça" foi elaborada pelos autores ROBBA e MACEDO (2003).

(2) Secretaria de Desenvolvimento da Cidade.

(3) Secretaria Municipal da Fazenda.

(4) Disponível em: http://geoweb.vitoria.es.gov.br.

\section{Bibliografia}

FAVOLE, Paolo. La plaza em la arquitectura contemporánea. Barcelona: Gustavo Gilli S. A., 1995.

LYALL, Surtherland. Landscape: diseño del espácio público. Parques. Plazas. jardines. Barcelona: Gustavo Gilli, 1991.

MACEDO, Silvio Soares. Quadro do paisagismo no Brasil. São Paulo: Editora da Universidade de São Paulo/Imprensa Oficial do Estado de São Paulo, 1999.

MACEDO, Silvio Soares; SAKATA, Francine Gramacho. Parques urbanos no Brasil. São Paulo: Editora da Universidade de São Paulo/Imprensa Oficial do Estado de São Paulo, 2003.

MACIEL, Marieta Cardoso. O projeto em arquitetura paisagística: Praças e parques públicos de Belo Horizonte. 1983. Tese (Doutorado) - Faculdade de Arquitetura e Urbanismo, Universidade de São Paulo, São Paulo, 1983.

ROBBA, Fábio. O desenho da praça pública contemporânea brasileira. Disponível em: <www.vitruvius.com.br>. Acesso em 2003.

ROBBA, Fábio; MACEDO, Silvio Soares. Praças brasileiras. São Paulo: Editora da Universidade de São Paulo/Imprensa Oficial do Estado de São Paulo, 2003.

RODRIGUES, Ferdinando de Moura. Forma, imagem e significado em estruturas urbanas centrais. Niterói: EdUFF/ ProEditores, 2005.

SEGAWA, Hugo. Ao amor do público: Jardins do Brasil (1779-1911). São Paulo: Nobel, 1996. 